\title{
In silico molecular docking and in vitro antimicrobial efficacy of phytochemicals against multi-drug-resistant enteroaggregative Escherichia coli and non-typhoidal Salmonella spp.
}

Padikkamannil Abishad ${ }^{1}$, Pollumahanti Niveditha², Varsha Unni ${ }^{1}$, Jess Vergis ${ }^{1}$, Nitin Vasantrao Kurkure ${ }^{3}$, Sandeep Chaudhari ${ }^{3}$, Deepak Bhiwa Rawool ${ }^{2}$ and Sukhadeo Baliram Barbuddhe $2^{2^{*}}$ (1)

\begin{abstract}
Background: In the wake of emergence of antimicrobial resistance, bioactive phytochemical compounds are proving to be important therapeutic agents. The present study envisaged in silico molecular docking as well as in vitro antimicrobial efficacy screening of identified phytochemical ligands to the dispersin (aap) and outer membrane osmoporin (OmpC) domains of enteroaggregative Escherichia coli (EAEC) and non-typhoidal Salmonella spp. (NTS), respectively.

Materials and methods: The evaluation of drug-likeness, molecular properties, and bioactivity of the identified phytocompounds (thymol, carvacrol, and cinnamaldehyde) was carried out using Swiss ADME, while Protox-II and StopTox servers were used to identify its toxicity. The in silico molecular docking of the phytochemical ligands with the protein motifs of dispersin (PDB ID: 2jvu) and outer membrane osmoporin (PDB ID: 3uU2) were carried out using AutoDock v.4.20. Further, the antimicrobial efficacy of these compounds against multi-drug resistant EAEC and NTS strains was determined by estimating the minimum inhibitory concentrations and minimum bactericidal concentrations. Subsequently, these phytochemicals were subjected to their safety (sheep and human erythrocytic haemolysis) as well as stability (cationic salts, and $\mathrm{pH}$ ) assays.
\end{abstract}

Results: All the three identified phytochemicals ligands were found to be zero violators of Lipinski's rule of five and exhibited drug-likeness. The compounds tested were categorized as toxicity class-4 by Protox-II and were found to be non- cardiotoxic by StopTox. The docking studies employing 3D model of dispersin and ompC motifs with the identified phytochemical ligands exhibited good binding affinity. The identified phytochemical compounds were observed to be comparatively stable at different conditions (cationic salts, and pH); however, a concentration-dependent increase in the haemolytic assay was observed against sheep as well as human erythrocytes.

*Correspondence: barbuddhesb@gmail.com

${ }^{2}$ ICAR-National Research Centre on Meat, Chengicherla, Boduppal Post, 500092 Hyderabad, India

Full list of author information is available at the end of the article permits use, sharing, adaptation, distribution and reproduction in any medium or format, as long as you give appropriate credit to the original author(s) and the source, provide a link to the Creative Commons licence, and indicate if changes were made. The images or other third party material in this article are included in the article's Creative Commons licence, unless indicated otherwise in a credit line to the material. If material is not included in the article's Creative Commons licence and your intended use is not permitted by statutory regulation or exceeds the permitted use, you will need to obtain permission directly from the copyright holder. To view a copy of this licence, visit http://creativecommons.org/licenses/by/4.0/. The Creative Commons Public Domain Dedication waiver (http://creativeco mmons.org/publicdomain/zero/1.0/) applies to the data made available in this article, unless otherwise stated in a credit line to the data. 
Conclusions: In silico molecular docking studies provided useful insights to understand the interaction of phytochemical ligands with protein motifs of pathogen and should be used routinely before the wet screening of any phytochemicals for their antibacterial, stability, and safety aspects.

Keywords: Phytochemical, Docking, Enteroaggregative E. coli, Non-typhoidal Salmonella

\section{Background}

Food-borne illnesses constitute a nagging public health issue that causes considerable impediments to the global health and economy, owing to the globalization and active food trade across countries [1]. Contamination of foods can lead to food-borne illnesses that can occur at any point of production, processing, distribution, and consumption. This emerging public health problem causes considerable obstruction to socio-economic development as well as contributes significantly to the global burden of disability, morbidity, and mortality. Global estimates correlated foodborne illnesses with nearly 600 million episodes, 4,20,000 mortality, and 33 million disability-adjusted life years [2].

Enteric bacterial pathogens namely, Salmonella spp. and Escherichia coli are important 'priority' listed foodborne pathogens [3]. Non-typhoidal Salmonella (NTS) serovars and diarrhoeagenic E. coli (DEC) pathotypes constitute the leading causes of gastrointestinal infections worldwide $[4,5]$. Globally, the NTS serovars are responsible for approximately 153 million cases of gastroenteritis and 7000 deaths annually [6]. Besides, the DEC pathotypes especially, enteroaggregative $E$. coli (EAEC), are long been associated with foodborne outbreaks globally, thereby posing risk to global food safety and public health $[5,7]$. The occurrence of NTS and EAEC has widely been reported from both developed as well as developing countries $[4,5,8]$. Antimicrobials have recently been employed on a larger scale as prophylactic as well as therapeutic agents to combat infections [9]. In recent times, the evolution and natural selection of bacteria along with the unprecedented use of antimicrobials have contributed to an alarming increase in antimicrobial resistance (AMR) [10]. Moreover, it has also been estimated that the mortality rate by way of AMR would increase to the tune of 10 million by 2050 , which would further decrease the gross domestic product (GDP) by $3.50 \%$, resulting in an overall global economic loss of nearly USD 100 trillion [11]. Of late, multi-drug resistance among the NTS serotypes and EAEC has been reported from various sources $[5,12]$. Hence, the focus has primarily been shifted towards alternative therapeutic strategies to counter the menace of AMR, apart from the routinely employed antibiotics [13].

Recently, the use of phytochemicals has emerged as one of the promising holistic alternative approaches with minimal side effects [14]. The bioactive phytochemicals and essential oils were found to have exerted significant antimicrobial activity against Salmonella spp. and E. coli [15]. The screening of molecules with potential bioactivity is quite costly and may consume time. However, computer-aided drug design (CADD) could save time as well as the cost of synthesis of molecules and would ultimately curtail the cost of research [16]. In silico molecular docking is one such CADD technique that would virtually predict the binding efficacy as well as the structure-based drug design [16]. Moreover, the molecular docking provides successful insights into the structure-activity relationships, mode of activity, and further analysis from protein-ligand interaction [17]. Such studies would culminate in the development of novel drug molecules at a faster pace against infectious pathogens. Additionally, the physicochemical properties of the molecule would provide vital information on the initial phase of drug development [16, 17].

The phytochemical compounds-monoterpenoids (thymol and carvacrol) and phenylpropanoid (cinnamaldehyde) are generally considered safe for human consumption and have been approved by Food and Drug Administration (FDA) for being used as food additives. Moreover, these phytocompounds have been extracted from various indigenous herbs located in different parts of India [18-21]. The objective of the present study was to study in silico absorption, distribution, metabolism, excretion, and toxicity (ADMET) analysis of the identified phytochemicals viz., thymol, carvacrol, and cinnamaldehyde, followed by in silico blind docking approach to check their ligand binding affinities to the outer membrane osmoporin protein (ompC) of Salmonella Enteritidis and/or Salmonella Typhimurium, and dispersin (aap) domain of EAEC. Later, the in silico approach was vetted by performing in vitro antimicrobial efficacy of these phytochemicals against the multi-drug resistant (MDR)-strains of NTS and EAEC. Also, in vitro safety and stability aspects of the identified phytochemicals were explored.

\section{Results}

The EAEC $(n=3)$ and NTS $(n=3)$ strains used in this study were multi-drug resistant. The results of antibiotic susceptibility testing of the test strains are given as Additional file 1: Table S1. 


\section{ADMET analysis}

The ADME analysis (physicochemical properties, water solubility, lipophilicity, pharmacokinetics, drug likeness and medicinal chemistry) of the three phytochemicals tested (thymol, carvacrol and cinnamaldehyde) was carried out by Swiss ADME software (Table 1).

All the phytochemicals tested revealed drug likeness with no violation to Lipinski's rule of five. Also, all the phytochemical compounds exhibited a bioavailability score of 0.55 , indicating their drug- like properties. Besides, all the phytochemicals under study were found to be absorbed in the gastrointestinal tract and could cross the blood brain barrier. The topological polar surface area ranged from 17.07 to $20.23 \AA^{2}$, while the consensus $\log$ Po/w (indicator of lipophilicity) was observed to range from 1.97 to 2.82 . Besides, the compounds tested exhibited no permeability glycoprotein substrate (P-gp). Additionally, all the phytochemicals tested interacted only with CYP1A2 isoenzyme of cytochrome P family, conferring their effectiveness with minimal toxicity (Table 1).

The bioavailability radar plots of the tested phytochemicals (Additional file 1: Fig. S1) indicated that the phytochemicals were fairly inside the pink area, indicating their drug-likelihood with a better bioavailability profile. Additionally, the boiled egg graph of thymol, carvacrol and cinnamaldehyde appeared within the yellow region (yolk) with a red point, predicting their brain penetrability acting as a non-substrate of P-gp (Additional file 1: Fig. S2).

Further, the in-silico toxicity properties of the phytochemicals were evaluated by Protox- II and StopTox softwares (Table 2). The predicted $\mathrm{LD}_{50}(\mathrm{mg} / \mathrm{kg})$ for all the phytochemicals tested ranged from 640 to 1850; hence, were categorized as toxicity class- 4 by Protox-II. Further, all the tested phytocompounds were found to be noncardiotoxic by StopTox software, based on hERG liability prediction, with the confidence levels ranges between 50 and $60 \%$ (Table 2).

\section{Molecular docking using Autodock v.4.20}

Protonated low energy 3-D ligand conformation was prepared using Chem 3D v.16.0 software. Further, in silico molecular docking was carried out to estimate the binding energy and to demonstrate the protein-ligand interaction mechanism. All favourably docked structures gained from the molecular docking analysis of the tested phytochemical agents (thymol, carvacrol and cinnamaldehyde) inside the ompC and aap motifs are displayed in Figs. 1 and 2, respectively.

The binding free energy values observed for carvacrol $(-5.27 \mathrm{kcal} / \mathrm{mol})$, cinnamaldehyde $(-5.65 \mathrm{kcal} / \mathrm{mol})$ and thymol $(-4.97 \mathrm{kcal} / \mathrm{mol})$ were nearly equal for both the pathogens (Table 3). Carvacrol was found to interact with OmpC at active sites Leu332, Asp304, Asp33, Asn335 and Thr338, while interacted with aap at Phe60, Val70, Val46, Tyr23, Thr72, Phe50, Tyr87. Moreover, thymol was found to interact with the OmpC at sites Val218, Ala216, Thr239, Phe120 and Asn119, while with aap at Asp75, Ile76, Asn73, Thr72, Thr79 and Val84. Further, cinnamaldehyde interacted with $\mathrm{OmpC}$ at the active sites Ser187, Ile182, Phe186 and Tyr226, while with aap at sites Lys40, Val41, Trp5, Ser96, Ala7, Trp93, Ser98 and Val94 (Figs. 1 and 2). In brief, all the three studied phytochemical agents interacted firmly with the respective protein motifs and probably have significance as inhibitors of both aap (EAEC) and ompC (NTS).

\section{In vitro antimicrobial efficacy}

To corroborate the in silico prediction, MIC and MBC values of the phytochemicals were determined to assess their in vitro antimicrobial efficacy (Table 4). The MIC values of all the three phytochemicals tested ranged from 0.25 to $0.50 \mu \mathrm{l} / \mathrm{ml}$ for MDR-EAEC strains, 0.12 to $0.50 \mu \mathrm{l} / \mathrm{ml}$ for MDR-S. Enteritidis strains and for MDR$S$. Typhimurium strains, it ranged from 0.06 to $0.25 \mu \mathrm{l} /$ $\mathrm{ml}$. However, the $\mathrm{MBC}$ values obtained were either equal to or greater than the MIC values and varied with the strains under study (Table 4).

\section{In vitro safety assay}

A concentration-dependent haemolysis was observed with all the three phytochemicals, both in sheep as well as human 'O' erythrocytes. At $1 \mathrm{X}$ MIC level, minimal haemolysis was observed both in sheep and human RBCs. However, at $2 \mathrm{X}$ and $4 \mathrm{X}$ MIC levels, the haemolysis observed was minimal to moderate (less than $40 \%$ ), except in carvacrol (57 to $82 \%$ ) (Additional file 1: Table S2).

\section{In vitro stability assay \\ Effect of cationic salts}

The MIC values of thymol and cinnamaldehyde remained almost similar for the MDR-EAEC strains even after co-incubating with physiological concentration of cationic salts $(150 \mathrm{mM} \mathrm{NaCl}$ and $2 \mathrm{mM} \mathrm{MgCl} 2)$. However, a two- to four-fold increase in the MIC levels was observed when MDR-EAEC strains were co-incubated with carvacrol. The MDR-NTS strains tested exhibited a twoto four-fold increase in the MIC values of all the three tested phytochemicals while co-incubating with cationic salts (Additional file 1: Table S3a).

\section{Effect of $p H$}

As pH 2.0 did not favour the growth of MDR-EAEC and NTS strains tested, the antimicrobial efficacy for the 
Table 1 In silico ADME analysis of phytochemicals tested

\begin{tabular}{|c|c|c|c|c|}
\hline SI no. & Descriptors & Thymol & Carvacrol & Cinnamaldehyde \\
\hline \multicolumn{5}{|c|}{ Physicochemical properties } \\
\hline 1. & SMILE & $\operatorname{Cc1ccc}(c(c 1) O) C(C) C$ & $C C(\operatorname{clccc}(c(c 1) O) C) C$ & $\mathrm{O}=\mathrm{CC}=\mathrm{Cc} 1 \mathrm{ccccc} 1$ \\
\hline 2. & Formula & $\mathrm{C} 10 \mathrm{H} 14 \mathrm{O}$ & $\mathrm{C} 10 \mathrm{H} 14 \mathrm{O}$ & $\mathrm{C} 9 \mathrm{H} 8 \mathrm{O}$ \\
\hline 3. & Molecular weight (g/mol) & 150.22 & 150.22 & 132.16 \\
\hline 4. & Number of heavy atoms & 11 & 11 & 10 \\
\hline 5. & Number of aromatic heavy atoms & 6 & 6 & 6 \\
\hline 6. & Fraction Csp3 & 0.40 & 0.40 & 0.00 \\
\hline 7. & Number of rotatable bonds & 1 & 1 & 2 \\
\hline 8. & Number of H-bond acceptors & 1 & 1 & 1 \\
\hline 9. & Number of $\mathrm{H}$-bond donors & 1 & 1 & 0 \\
\hline 10. & Molar refractivity & 48.01 & 48.01 & 41.54 \\
\hline 11. & Topological polar surface area $\left(\AA^{2}\right)$ & 20.23 & 20.23 & 17.07 \\
\hline \multicolumn{5}{|c|}{ Lipophilicity } \\
\hline 12. & $\log P_{\mathrm{o} / \mathrm{w}}(\mathrm{iLOGP})$ & 2.32 & 2.24 & 1.65 \\
\hline 13. & $\log P_{\mathrm{o} / \mathrm{w}}(\mathrm{XLOGP3})$ & 3.30 & 3.49 & 1.90 \\
\hline 14. & $\log P_{\mathrm{o} / \mathrm{W}}(\mathrm{WLOGP})$ & 2.82 & 2.82 & 1.79 \\
\hline 15. & $\log P_{\mathrm{o} / \mathrm{w}}(\mathrm{MLOGP})$ & 2.76 & 2.76 & 2.01 \\
\hline 16. & $\log P_{\mathrm{o} / \mathrm{w}}(\mathrm{SILICOS}-\mathrm{IT})$ & 2.79 & 2.79 & 2.48 \\
\hline 17. & Consensus $\log P_{\mathrm{o} / \mathrm{w}}$ & 2.80 & 2.82 & 1.97 \\
\hline \multicolumn{5}{|c|}{ Water solubility } \\
\hline 18. & $\log S(E S O L)$ & -3.19 & -3.31 & -2.17 \\
\hline 19. & Solubility & $\begin{array}{l}9.74 \mathrm{e}-02 \mathrm{mg} / \mathrm{ml} \\
6.49 \mathrm{e}-04 \mathrm{~mol} / \mathrm{l}\end{array}$ & $\begin{array}{l}7.40 \mathrm{e}-02 \mathrm{mg} / \mathrm{ml} ; \\
4.92 \mathrm{e}-04 \mathrm{~mol} / /\end{array}$ & $\begin{array}{l}8.97 \mathrm{e}-01 \mathrm{mg} / \mathrm{ml} \\
6.79 \mathrm{e}-03 \mathrm{~mol} / \mathrm{l}\end{array}$ \\
\hline 20. & Class & Soluble & Soluble & Soluble \\
\hline 21. & $\log S($ Ali) & -3.40 & -3.60 & -1.88 \\
\hline 22. & Solubility & $\begin{array}{l}5.97 \mathrm{e}-02 \mathrm{mg} / \mathrm{ml} \\
3.98 \mathrm{e}-04 \mathrm{~mol} / \mathrm{l}\end{array}$ & $\begin{array}{l}3.79 \mathrm{e}-02 \mathrm{mg} / \mathrm{ml} \\
2.53 \mathrm{e}-04 \mathrm{~mol} / \mathrm{l}\end{array}$ & $\begin{array}{l}1.74 \mathrm{e}+00 \mathrm{mg} / \mathrm{ml} \\
1.31 \mathrm{e}-02 \mathrm{~mol} / \mathrm{l}\end{array}$ \\
\hline 23. & Class & Soluble & Soluble & Very soluble \\
\hline 24. & $\log S($ SILICOS-IT) & -3.01 & -3.01 & -2.40 \\
\hline 25. & Solubility & $\begin{array}{l}1.46 \mathrm{e}-01 \mathrm{mg} / \mathrm{ml} ; \\
9.71 \mathrm{e}-04 \mathrm{~mol} / \mathrm{l}\end{array}$ & $\begin{array}{l}1.46 \mathrm{e}-01 \mathrm{mg} / \mathrm{ml} \\
9.71 \mathrm{e}-04 \mathrm{~mol} / \mathrm{l}\end{array}$ & $\begin{array}{l}5.26 \mathrm{e}-01 \mathrm{mg} / \mathrm{ml} \\
3.98 \mathrm{e}-03 \mathrm{~mol} / \mathrm{l}\end{array}$ \\
\hline 26. & Class & Soluble & Soluble & Soluble \\
\hline \multicolumn{5}{|c|}{ Pharmacokinetics } \\
\hline 27. & Gl absorption & High & High & High \\
\hline 28. & BBB permeant & Yes & Yes & Yes \\
\hline 29. & P-gp substrate & No & No & No \\
\hline 30. & CYP1A2 inhibitor & Yes & Yes & No \\
\hline 31. & CYP2C19 inhibitor & No & No & No \\
\hline 32. & CYP2C9 inhibitor & No & No & No \\
\hline 33. & CYP2D6 inhibitor & No & No & No \\
\hline 34. & CYP3A4 inhibitor & No & No & No \\
\hline 35. & Log $K_{p}($ skin permeation) $(\mathrm{cm} / \mathrm{s})$ & -4.87 & -4.74 & -5.76 \\
\hline \multicolumn{5}{|c|}{ Drug-likeness } \\
\hline 36. & Lipinski & Yes; 0 violation & Yes; 0 violation & Yes; 0 violation \\
\hline 37. & Ghose & No; 1 violation: $\mathrm{MW}<160$ & $\begin{array}{l}\text { No; } 1 \text { violation: } \\
\mathrm{MW}<160\end{array}$ & No; 2 violations: $\mathrm{MW}<160$, \#atoms $<20$ \\
\hline 38. & Veber & Yes & Yes & Yes \\
\hline 39. & Egan & Yes & Yes & Yes \\
\hline 40. & Muegge & $\begin{array}{l}\text { No; } 2 \text { violations: } \mathrm{MW}<200 \text {, } \\
\text { Heteroatoms }<2\end{array}$ & $\begin{array}{l}\text { No; } 2 \text { violations: } \\
\text { MW }<200 \text {, } \\
\text { Heteroatoms }<2\end{array}$ & No; 2 violations: $M W<200$, Heteroatoms $<2$ \\
\hline
\end{tabular}


Table 1 (continued)

\begin{tabular}{|c|c|c|c|c|}
\hline SI no. & Descriptors & Thymol & Carvacrol & Cinnamaldehyde \\
\hline 41. & Bioavailability score & 0.55 & 0.55 & 0.55 \\
\hline \multicolumn{5}{|c|}{ Medicinal chemistry } \\
\hline 42. & PAINS & 0 Alert & 0 Alert & 0 Alert \\
\hline 43. & Brenk & 0 Alert & 0 Alert & 2 Alerts: aldehyde, michael_acceptor_1 \\
\hline 44. & Lead likeness & No; 1 violation: $M W<250$ & $\begin{array}{l}\text { No; } 1 \text { violation: } \\
\text { MW }<250\end{array}$ & No; 1 violation: $M W<250$ \\
\hline 45. & Synthetic accessibility & 1.00 & 1.00 & 1.65 \\
\hline
\end{tabular}

Table 2 In silico toxicity analysis of phytochemicals tested

\begin{tabular}{|c|c|c|c|c|}
\hline \multirow[t]{2}{*}{ SI no. } & \multirow[t]{2}{*}{ Phytochemicals } & \multicolumn{2}{|c|}{$\begin{array}{l}\text { Oral toxicity of } \\
\text { phytochemicals } \\
\text { (PROTOXII) }\end{array}$} & \multirow{2}{*}{$\begin{array}{l}\text { hERG liability } \\
\text { prediction/ } \\
\text { confidence } \\
\text { (StopTox) }\end{array}$} \\
\hline & & $\begin{array}{l}\text { Predicted } \\
\text { LD50 (mg/ } \\
\text { kg) }\end{array}$ & $\begin{array}{l}\text { Predicted } \\
\text { toxicity } \\
\text { class }\end{array}$ & \\
\hline 1. & Thymol & 640 & 4 & $\begin{array}{l}\text { Non-cardiotoxic } \\
(60)\end{array}$ \\
\hline 2. & Carvacrol & 810 & 4 & $\begin{array}{l}\text { Non-cardiotoxic } \\
\text { (50) }\end{array}$ \\
\hline 3. & Cinnamaldehyde & 1850 & 4 & $\begin{array}{l}\text { Non-cardiotoxic } \\
(60)\end{array}$ \\
\hline
\end{tabular}

phytochemicals could not be determined. The MIC values of thymol and cinnamaldehyde remained unaltered with MDR-EAEC strains while treated at varied $\mathrm{pH}(4.0$ to 8.0); however, a two- to four-fold increase in the MIC values was observed with the carvacrol treatment. Nevertheless, the MDR-strains of NTS exhibited a two- to four-fold increase in the MIC values, irrespective of the phytochemicals tested (Additional file 1: Table S3b).

The results of in vitro antimicrobial assay (determination of MIC and MBC values; Table 4) correlated well with the in-silico results (drug likeness, violation to Lipinski's rule of five) obtained from Swiss ADME data (Table 1). Besides, the results of in silico toxicity assay demonstrated by Protox-II and StopTox softwares (Table 2) were found to be in consonance with the in vitro haemolytic assay results (Additional file 1: Table S2). In short, it was observed that the in silico ADMET analysis correlated well with the in vitro assays performed.

\section{Discussion}

Considering the pace at which drug resistance is emerging among the pathogens of public health significance, drug discovery, design and their development is the need of the hour [22]. Researchers across the globe have been searching for the novel alternative therapeutic strategies or even drug re-purposing [23, 24]. Phytochemicals constitute one such promising alternative
[25]. Phytochemicals have been reported to possess a broad-spectrum of antibacterial activities against various pathogens of public health importance [26]. However, in vitro screening of phytochemical compounds for their antibacterial efficacy and toxicity studies would consume more time. Hence, in silico computational approaches associated with chemoinformatics, molecular docking, as well as artificial intelligence, have considerably increased during the past decade in the domain of drug design, development, and discovery [27, 28]. Employing in silico approaches would, therefore, enable virtual screening of molecules which would result in providing better chances of discovering suitable drug candidates in considerably less time and cost. Several structure-based and ligand-based molecular docking approaches are currently available to facilitate high-throughput drug discovery $[16,27]$. In the present study, an in silico molecular docking of three identified phytochemicals (thymol, carvacrol, and cinnamaldehyde) to the ompC and aap protein domains of NTS and EAEC strains, respectively was performed. The in-silico data obtained by docking tools was further validated with in vitro antimicrobial efficacy of these phytochemicals against the MDR-strains of NTS and EAEC.

Obnoxious pharmacokinetic properties and toxicity remain hurdles in the development of drug candidates at clinical trials. Hence, identification of suitable candidates with drug-likeness along with sufficient information regarding absorption, distribution, metabolism, excretion, and toxicity (ADMET) is required during the initial phase of drug discovery [28]. The identified phytochemical compounds-monoterpenoids (thymol and carvacrol) and phenylpropanoid (cinnamaldehyde) are generally considered safe for human consumption and have been approved by Food and Drug Administration (FDA) for being used as food additives [18, 19, 21]. However, their ADME profile in connection with in vitro antimicrobial efficacy studies against MDR pathogens has rarely been undertaken. In the present study, the Swiss ADME server was used to analyse various ADME descriptors like, physiochemical properties, pharmacokinetics, solubility, lipophilicity, drug-likeness based on violation of Lipinski's 

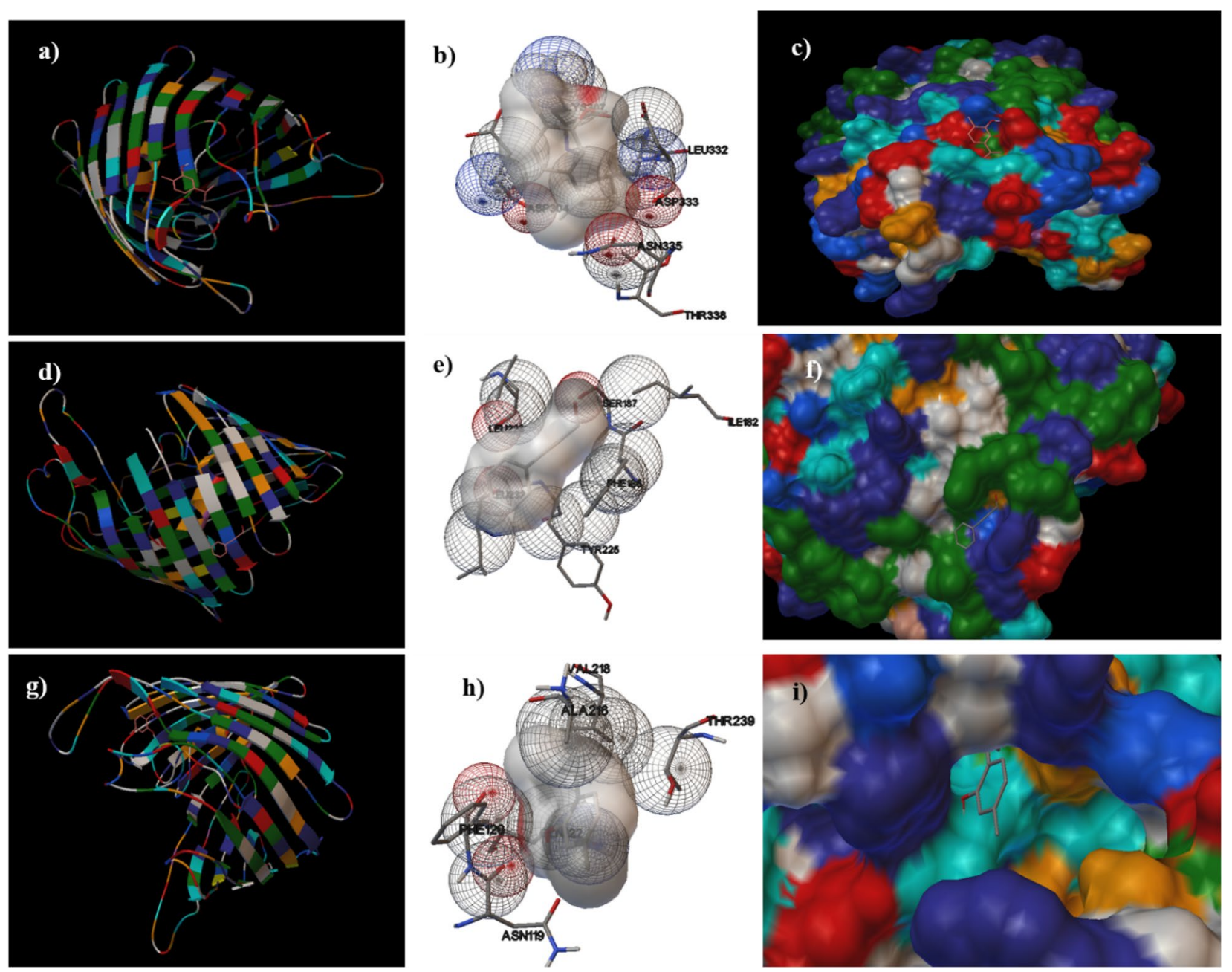

Fig. $12-D$ and 3-D interactions of molecular docking of tested phytochemicals inside ompC. The horizontal rows denote interactions with carvacrol $(\mathbf{a}-\mathbf{c})$, cinnamaldehyde $(\mathbf{d}-\mathbf{f})$ and thymol $(\mathbf{g}-\mathbf{i})$, respectively; $\mathbf{a}, \mathbf{d}, \mathbf{g}$ denotes secondary structures of protein-ligand complexes; $\mathbf{b}, \mathbf{e}, \mathbf{h}$ protein-ligand interaction, whereas $\mathbf{c}, \mathbf{f}$, $\mathbf{i}$ denotes $3-D$ conformation of complexes

rule of five and medicinal chemistry [29]. In silico ADME prediction of the three identified phytochemical compounds established drug-likeness as evidenced by no violation to its Lipinski's rule of five and the obtained bioavailability score (0.55). Further, the red line of the compound in the bioavailability radar plot must be within the pink area to deem the compound as drug-like. The radar plots of thymol and carvacrol were observed completely within the pink area, while that of cinnamaldehyde was fairly within the pink area justifying its drug-likeness. Besides, the ADME data along with the boiled egg model revealed a better gastrointestinal absorption and permeation of the blood-brain barrier by all the tested phytochemicals [29].

It is well understood that the P-gp and cytochrome P450 (CYP) help in biotransformation of xenobiotics to protect tissues [30]. In this study, the phytochemicals exhibited no-P-gp substrate. The P-gp is indicated as the most important member of ATP-binding cassette transporters which is pivotal to evaluate the protective efflux of biological membranes (GI tract or brain) from xenobiotics [29, 31]. Moreover, all the three phytochemicals tested interacted only with CYP1A2 isoenzyme of CYP family, conferring its effectiveness with minimal toxicity [31].

Further, to investigate the in-silico toxicity parameters, Protox-II [32] and StopTox [33] machine learning apps were used. The predicted $\mathrm{LD}_{50}(\mathrm{mg} / \mathrm{kg})$ for the three phytochemicals tested ranged from 640 to 1850; hence were categorized as toxicity class- 4 by Protox-II, indicating that the phytochemicals might be harmful if swallowed $\left(300<\mathrm{LD}_{50} \leq 2000\right)$. Further, all the tested 


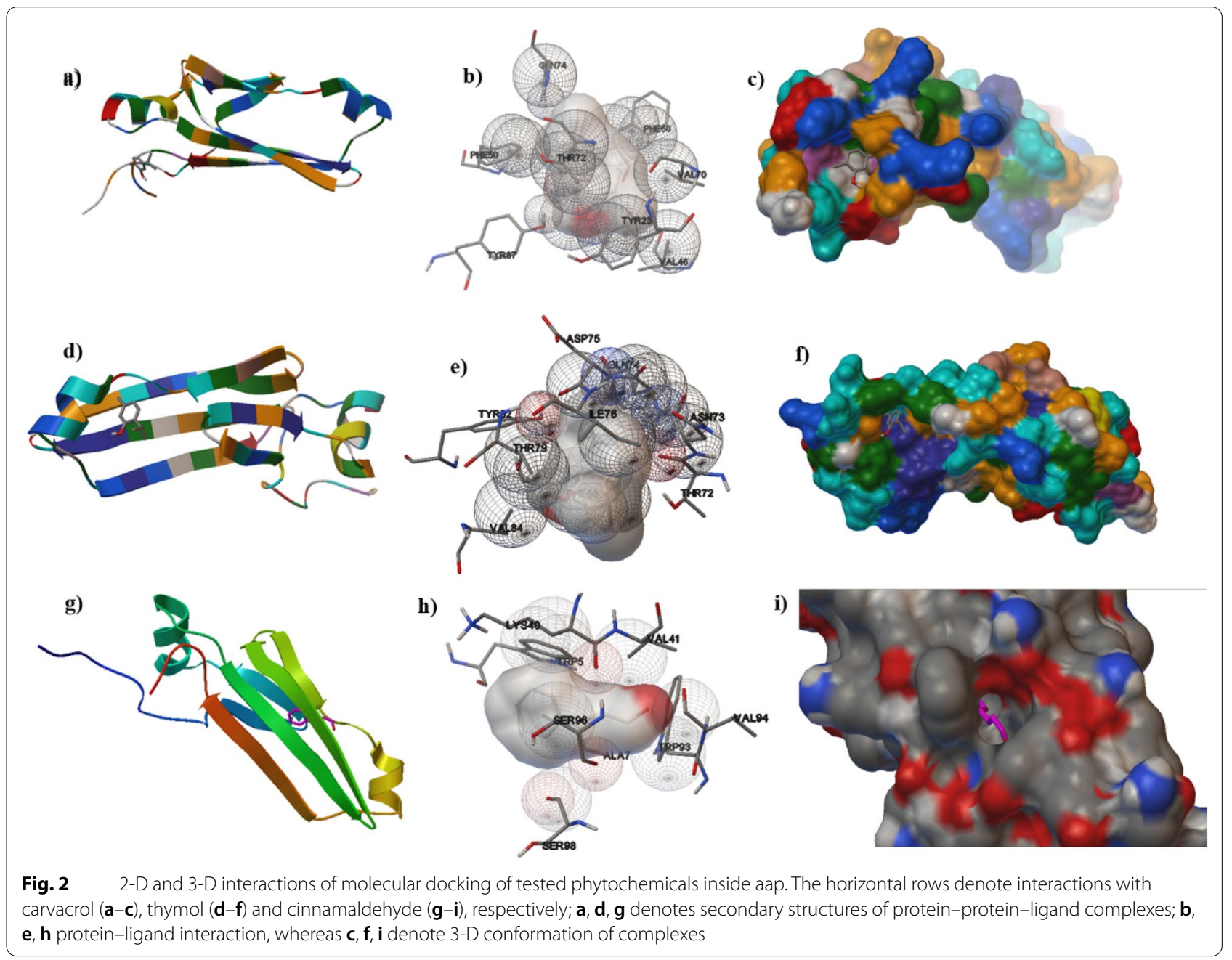

Table 3 Binding affinity values of tested phytochemicals to dispersin and osmoporin (OmpC) proteins of EAEC and NTS

\begin{tabular}{|c|c|c|c|c|c|c|c|}
\hline \multirow[t]{2}{*}{ SI. No. } & \multirow[t]{2}{*}{ Phytochemicals } & \multicolumn{3}{|l|}{ EAEC } & \multicolumn{3}{|l|}{ NTS } \\
\hline & & $\begin{array}{l}\text { Binding energy } \\
\text { (kcal/mol) }\end{array}$ & Ligand efficiency & $\begin{array}{l}\text { Inhibition } \\
\text { constant }(\mu \mathrm{M})\end{array}$ & $\begin{array}{l}\text { Binding energy } \\
\text { (kcal/mol) }\end{array}$ & Ligand efficiency & $\begin{array}{l}\text { Inhibition } \\
\text { constant } \\
(\mu \mathrm{M})\end{array}$ \\
\hline 1. & Carvacrol & -5.27 & -0.48 & 137.22 & -4.49 & -0.41 & 510.49 \\
\hline 2. & Cinnamaldehyde & -5.65 & -0.57 & 71.61 & -4.65 & -0.47 & 390.26 \\
\hline 3. & Thymol & -4.97 & -0.45 & 227.5 & -4.97 & -0.45 & 226.89 \\
\hline
\end{tabular}

phytocompounds were found to be non-cardiotoxic by StopTox software, based on hERG liability prediction, with the confidence levels ranging between 50 and $60 \%$. However, the obtained toxicity findings need to be correlated with the in vitro safety assays before their assessment in suitable laboratory animal models.

The in silico ADMET analysis encouraged the phytochemicals to be employed further for Autodock-based computational docking studies [34] to ompC of NTS [35] and aap of EAEC [36]. In this study, ligand-based interaction with the protein domains of pathogens was investigated using blind docking employing Autodock software. Osmoporin (ompC), present in the Salmonella spp., is responsible for its survival and pathogenicity and plays a crucial role in diffusing hydrophilic compounds [35]. Moreover, dispersin (aap) present in the EAEC strains is highly immunogenic and represents a class of aggregative factors which are responsible for its functional attribute 
Table 4 MIC and MBC values of phytochemicals against MDR-strains of EAEC and NTS

\begin{tabular}{|c|c|c|c|c|c|c|c|}
\hline \multirow[t]{2}{*}{ Isolate ID } & \multirow[t]{2}{*}{ Source of isolate } & \multicolumn{2}{|l|}{ Carvacrol } & \multicolumn{2}{|c|}{ Cinnamaldehyde } & \multicolumn{2}{|l|}{ Thymol } \\
\hline & & $\mathrm{MIC}(\mu \mathrm{l} / \mathrm{ml})$ & $\begin{array}{l}\text { MBC } \\
(\mu \mathrm{l} / \mathrm{ml})\end{array}$ & MIC $(\mu \mathrm{l} / \mathrm{ml})$ & $\begin{array}{l}\text { MBC } \\
(\mu \mathrm{l} / \mathrm{ml})\end{array}$ & $\mathrm{MIC}(\mu \mathrm{l} / \mathrm{ml})$ & $\begin{array}{l}\text { MBC } \\
(\mu \mathrm{l} / \mathrm{ml})\end{array}$ \\
\hline EAEC (E1) & Infant diarrhoea & 0.25 & 1.0 & 0.50 & 0.50 & 0.25 & 0.25 \\
\hline EAEC (E2) & & 0.50 & 0.50 & 0.50 & 1.0 & 0.25 & 0.50 \\
\hline EAEC (E3) & & 0.25 & 0.50 & 0.25 & 0.50 & 0.25 & 0.25 \\
\hline S. Enteritidis (S1) & Poultry droppings & 0.12 & 0.50 & 0.12 & 0.50 & 0.12 & 0.50 \\
\hline S. Enteritidis (S2) & & 0.25 & 0.50 & 0.12 & 0.50 & 0.25 & 0.50 \\
\hline S. Enteritidis (S3) & & 0.25 & 0.50 & 0.12 & 0.50 & 0.25 & 0.50 \\
\hline S. Typhimurium (ST1) & & 0.12 & 0.50 & 0.25 & 0.50 & 0.25 & 0.50 \\
\hline S. Typhimurium (ST2) & & 0.12 & 0.50 & 0.25 & 0.50 & 0.25 & 0.50 \\
\hline S. Typhimurium (ST3) & & 0.12 & 0.50 & 0.12 & 1.0 & 0.06 & 0.50 \\
\hline
\end{tabular}

[36]. The binding free energy values observed for carvacrol, cinnamaldehyde, and thymol were nearly equal for the protein domains of both the pathogens studied. All the studied phytochemical agents interacted firmly with the respective protein motifs and probably have significance as inhibitors of both ompC (NTS) and aap (EAEC). This observed high binding energies obtained during molecular docking would be due to the strong hydrophobic interactions between the phytochemical ligands and the protein motifs-aap and ompC. The in-silico computational data hence obtained needs to be validated with the in vitro antimicrobial efficacy studies.

The antimicrobial efficacy of phytochemicals under study was determined by MIC and MBC values. The MIC values of all the three phytochemicals tested ranged from 0.25 to $0.50 \mu \mathrm{l} / \mathrm{ml}$ for MDR-EAEC strains, 0.06 to $0.50 \mu \mathrm{l} /$ $\mathrm{ml}$ for MDR-NTS strains. However, the MBC values obtained were either equal to or greater than the MIC values. These varied MIC and MBC values of the phytochemicals tested could either be due to strain variation, the difference in the bacterial virulence factors, or structural differences in the bacterial membranes. Moreover, the observed in silico docking results were found to correlate well with the in vitro antimicrobial assays [31, 37].

Further, the computational toxicity assays need to be correlated with the in vitro safety assay, before being passed on for in vivo clinical trials. Therefore, a haemolytic assay based on sheep and human ' $\mathrm{O}$ ' $\mathrm{RBCs}$ was employed to ensure the safety profile of phytochemicals. A concentration-dependent haemolytic assay was observed with all three phytochemicals. At $1 \mathrm{X}$ MIC level, minimal hemolysis was observed both in sheep and human RBCs; however, at $2 \mathrm{X}$ and $4 \mathrm{X}$ MIC levels, the haemolysis observed was minimal to moderate, except in carvacrol. An improved specificity of phytochemicals against the bacterial cells and reduction in the haemolytic activity could further be accomplished by increasing the net charge and/or employing conjugation with nanoparticles [38]. The nanotechnological interventions are therefore aimed at delivery of drugs (including phytochemicals) with an intention to effect site-directed drug delivery, reduction in the toxicity with non-compromised safety and therapeutic efficacy by minimizing the concentration of the drug with improved bioavailability $[39,40]$.

Generally, bioactive phytochemical compounds get degraded in the gastrointestinal tract because of their poor stability [41]; hence, the in vitro stability assays $(\mathrm{pH}$, and cationic salts) were employed for the identified phytochemical compounds. In this study, thymol and cinnamaldehyde tested retained their antimicrobial activities even after subjecting them to varied stability conditions for MDR-EAEC strains, whereas slight decrease in the antimicrobial efficacy was observed against MDR-NTS strains tested. Moreover, carvacrol exhibited a slight increase in the MIC values for all the MDR strains tested. The stability of phytochemical compounds could be improved by nanobiotechnological interventions using a suitable delivery system [41] to get it protected from external as well as biological influences.

\section{Conclusion}

The present study envisaged in silico ADMET analysis, molecular docking as well as in vitro antimicrobial efficacy screening of three identified phytochemical ligands (thymol, carvacrol, and cinnamaldehyde) to the dispersin (aap) and outer membrane osmoporin (ompC) domains of EAEC and NTS, respectively. In silico ADMET prediction and molecular docking studies exhibited a good correlation with the in vitro antimicrobial efficacy studies. The identified phytochemical compounds were further observed to be comparatively stable at different conditions (cationic salts, and $\mathrm{pH}$ ); however, a 
concentration-dependent increase in the haemolytic assay was observed against sheep as well as human ' $O$ ' erythrocytes. Hence, we propose to conduct in silico computation approaches (ADMET analysis, molecular docking) as a high throughput antimicrobial screening tool to provide successful insights for exploring the interaction of phytochemical ligands with various pathogens.

\section{Materials and methods}

\section{Bacterial strains}

The characterised MDR field strains of EAEC (E1; E2; E3), S. Enteritidis (S1; S2; S3), and S. Typhimurium (ST1; ST2; ST3) maintained in the laboratory repository of Meat Safety Laboratory of ICAR-National Research Centre on Meat, Hyderabad re-validated using PCR assays $[42,43]$ were used to evaluate the in vitro antibacterial efficacy of phytochemicals. E. coli ATCC 25922 was used as the quality control strain.

\section{Phytochemicals}

The phytochemical molecules used in this assay viz., thymol, carvacrol, and cinnamaldehyde (Sigma Aldrich, USA) were retrieved from a literature survey [18-21] for ligand preparation against the protein motifs of the selected pathogens.

\section{In silico assays}

\section{Selection of protein motifs}

The chemical structures of the identified phytochemical ligands retrieved from the PubChem-NCBI database were drawn using Chem 3D v.16.0 software. The protein motifs of EAEC and NTS selected from the protein data bank (PDB) were dispersin (PDB ID: 2jvu) and outer membrane osmoporin (PDB ID: 3uu2), respectively.

\section{In silico absorption, distribution, metabolism, excretion, and toxicity (ADMET) analysis}

The identified phytochemicals were analysed for their ADMET analysis using Swiss ADME server (http://www. swissadme.ch/index.php). This server evaluates the compounds for their physicochemical properties, lipophilicity, water solubility, pharmacokinetics, drug likeness and medicinal chemistry. Further, the toxicity properties of the identified phytochemicals were analysed using online servers, Protox-II (https://tox-new.charite.de/protox_II/) [32] and StopTox (https://stoptox.mml.unc.edu/) [33]. Protox-II predicted the $\mathrm{LD}_{50}(\mathrm{mg} / \mathrm{kg})$ of the identified ligands and toxicity class, whereas StopTox identified cardiotoxicity (hERG liability prediction).

\section{Molecular docking using Autodock v.4.20}

The protonated low energy 3-D phytochemical ligand conformation was prepared using Chem 3D v.16.0 software. A blind docking employing automated docking software Autodock v.4.20 [34] was used to evaluate the binding affinity of ligands to the aap and ompC motifs of EAEC and NTS, respectively. The target proteins were prepared by removal of ligand, water molecule, hetero atoms, and co-crystallised solvents; non-polar hydrogens were merged and Gasteiger charges and polar-charged hydrogen were added. Further, a grid map was generated with a dimension of $60 \times 60 \times 60$ points with a spacing of $0.375 \AA$ and the Lamarckian genetic algorithm was used to analyse the docking probability. The configuration files created for both the proteins under study generated ten best poses for each of the ligands and scored using Autodock function; the ligands were ranked based on the docked energy. The results of molecular docking were observed using Pymol viewer.

\section{In vitro assays}

Determination of minimum inhibitory concentration and minimum bactericidal concentration

The antimicrobial efficacy of identified phytochemicals against multi-drug resistant EAEC and NTS strains was determined by estimating the minimum inhibitory concentration (MIC) and minimum bactericidal concentrations (MBC).

The MIC was determined by incubating $50 \mu \mathrm{l}$ of the individual test cultures $\left(1 \times 10^{7} \mathrm{CFU} / \mathrm{ml}\right)$ in cationadjusted Mueller Hinton (CA-MH) broth medium $(50 \mu \mathrm{l})$ with decreasing concentrations of phytochemicals in 96-well flat-bottom microtiter plates for $24 \mathrm{~h}$. Subsequent to the incubation period, resazurin dye $(0.015 \%)$ was added to all the wells to determine the dye reduction (pink) and thereby the bacterial inhibition. The lowest concentration of phytochemicals without visible growth was designated as MIC, while the MBC of phytochemicals was estimated by plating $10 \mu \mathrm{l}$ aliquots from each well revealing no visible growth in $\mathrm{MH}$ agar plates (HiMedia, Mumbai, India). The lowest concentration of the phytochemicals which revealed $99.9 \%$ killing of the test culture was defined as the $\mathrm{MBC}$ value of the corresponding phytochemical.

\section{Safety assays}

The haemolytic assay of the individual phytochemical was performed by measuring the release of haemoglobin from sheep and human 'O' erythrocytes at $540 \mathrm{~nm}$ [44]. The percentage of haemolysis was calculated as $\left(\mathrm{A}_{\text {sample }}\right.$ $\left.-\mathrm{A}_{\mathrm{PBS}}\right) /\left(\mathrm{A}_{\text {Triton-X}}-\mathrm{A}_{\mathrm{PBS}}\right) \times 100$, in which $\mathrm{A}_{\text {sample }}$ is the 
absorbance of phytochemical treatment, $A_{P B S}$ is the absorbance of untreated control with PBS, and $\mathrm{A}_{\text {Triton- } \mathrm{X}}$ is the absorbance of lysed cells treated with Triton X-100 measured at $540 \mathrm{~nm}$.

\section{Stability assays}

To explore the utility of phytochemicals as therapeutic molecules and their stability, individual phytochemicals were exposed to cationic salts, and different $\mathrm{pH}$ levels followed by analysing their MIC and MBC values against test strains as described earlier.

In brief, to investigate the stability of phytochemicals at a physiological concentration of cationic salts $(150 \mathrm{mM}$ $\mathrm{NaCl}$ and $2 \mathrm{mM} \mathrm{MgCl}_{2}$ ), corresponding phytochemicals were co-incubated in the presence of $150 \mathrm{mM} \mathrm{NaCl}$ and $2 \mathrm{mM} \mathrm{MgCl}_{2}$, separately with each MDR-strains of pathogens in CA-MH broth [42] and then determined their antimicrobial efficacy. Further, the stability of individual phytochemicals at different $\mathrm{pH}$ concentrations (2.0, 4.0, 6.0, and 8.0) was tested by co-incubating each phytochemical and the MDR-strains of pathogens overnight at $37^{\circ} \mathrm{C}$ in $\mathrm{CA}-\mathrm{MH}$ under specific $\mathrm{pH}$.

Subsequent to exposure to varied conditions, the antimicrobial activity of the phytochemicals was estimated by determining their MIC and $\mathrm{MBC}$ values against all the selected MDR strains of EAEC, $S$. Enteritidis, and $S$. Typhimurium as described earlier.

\section{Supplementary Information}

The online version contains supplementary material available at https://doi. org/10.1186/s13099-021-00443-3.

Additional file 1: Table S1. Antibiotic susceptibility pattern of EAEC and NTS strains under study. Table S2. In vitro haemolytic assay of phytochemicals against MDR-strains of EAEC and NTS. Table S3. In vitro stability assays (a Cationic salts; b pH) of phytochemicals against MDRstrains of EAEC and NTS. Fig. S1. Bioavailability radar of phytochemicals under study. A Thymol; B Carvacrol; C Cinnamaldehyde. Fig. S2. Boiled egg graph of phytochemicals under study. A Thymol; B Carvacrol; C Cinnamaldehyde.

\section{Acknowledgements}

The authors thank Director, ICAR- National Research Centre on Meat, Hyderabad; Vice Chancellors and Directors of Research of KVASU and MAFSU; and Deans and respective Heads of Department of CVAS, Pookode and NVC, Nagpur for providing facilities for this research.

\section{Authors' contributions}

SBB, DBR, NVK and JV conceptualised the research; JV, PA, PN and VU performed assays and analysed the data; JV, PA, PN, SC and VU interpreted the data; JV, SC and PA drafted the manuscript. SBB, DBR and NVK revised the manuscript. All authors read and approved the final manuscript.

\section{Funding}

This work was supported by a financial grant from National Agricultural Science Fund (ICAR-NASF; NASF/ABA-8007) to SBB, DBR, JV, and NVK.
Availability of data and materials

All data generated or analysed during this study are included in this published article [and its supplementary information files].

\section{Declarations}

Ethics approval and consent to participate

Not applicable.

\section{Consent for publication}

Not applicable.

\section{Competing interests}

None to declare.

\section{Author details}

${ }^{1}$ Department of Veterinary Public Health, College of Veterinary and Animal Sciences, KVASU, 673576 Pookode, Wayanad, India. ${ }^{2}$ ICAR-National Research Centre on Meat, Chengicherla, Boduppal Post, 500092 Hyderabad, India. ${ }^{3}$ Nagpur Veterinary College, MAFSU, Seminary Hills, 440006 Nagpur, India.

Received: 25 March 2021 Accepted: 8 July 2021

Published online: 17 July 2021

\section{References}

1. Lee H, Yoon Y. Etiological agents implicated in foodborne illness world wide. Food Sci Ani Resour. 2021:41:1

2. World Health Organisation. Food safety. 2020. https://www.who.int/ news-room/fact-sheets/detail/food-safety. Accessed 22 Mar 2021

3. World Health Organisation. WHO estimates of the global burden of foodborne diseases. Foodborne disease burden epidemiology reference group 2007-2015. Geneva:WHO Press; 2015. https://www.who.int/iris/ handle/10665/199350. Accessed 22 Mar 2021.

4. Al-Rifai RH, Chaabna K, Denagamage T, Alali WQ. Prevalence of nontyphoidal Salmonella enterica in food products in the Middle East and North Africa: a systematic review and meta-analysis. Food Control. 2020;109:106908.

5. Cabrera-Sosa L, Ochoa TJ. Escherichia coli diarrhea. Hunter's Tropical Med Emerg Infect Dis. 2020;481-5.

6. Sharma J, Kumar D, Hussain S, Pathak A, Shukla M, Kumar VP, Anisha PN, Rautela R, Upadhyay AK, Singh SP. Prevalence, antimicrobial resistance and virulence genes characterization of nontyphoidal Salmonella isolated from retail chicken meat shops in Northern India. Food Control. 2019;102:104-11.

7. Aijuka M, Santiago AE, Girón JA, Nataro JP, Buys EM. Enteroaggregative Escherichia coli is the predominant diarrheagenic E. coli pathotype among irrigation water and food sources in South Africa. Int J Food Microbiol. 2018;278:44-51.

8. Sodagari HR, Habib I, Whiddon S, Wang P, Mohammed AB, Robertson I, Goodchild S. Occurrence and characterization of Salmonella isolated from table egg layer farming environments in Western Australia and insights into biosecurity and egg handling practices. Pathogens. 2020;9:56.

9. Tang KL, Caffrey NP, Nóbrega DB, Cork SC, Ronksley PE, Barkema HW, Polachek AJ, Ganshorn H, Sharma N, Kellner JD, Checkley SL. Comparison of different approaches to antibiotic restriction in food-producing animals: stratified results from a systematic review and meta-analysis. BMJ Global Health. 2019;4(4):e001710.

10. Zhen $X$, Lundborg CS, Sun X, Hu X, Dong H. Economic burden of antibiotic resistance in ESKAPE organisms: a systematic review. Antimicrob Resist Infect Control. 2019;8:1-23.

11. Taneja N, Sharma M. Antimicrobial resistance in the environment: The Indian scenario. Ind J Med Res. 2019;149:119.

12. Munyalo JA. Genotyping of multi-drug resistant non-typhoidal Salmonella: detection of fluoroquinolone and other multi-drug resistance determinants [Doctoral dissertation]. University of Nairobi; 2019. 
13. Thombre R, Jangid K, Shukla R, Dutta NK. Alternative therapeutics against antimicrobial-resistant pathogens. Front Microbiol. 2019;10:2173.

14. AlSheikh HM, Sultan I, Kumar V, Rather IA, Al-Sheikh H, Tasleem Jan A, Haq QM. Plant-based phytochemicals as possible alternative to antibiotics in combating bacterial drug resistance. Antibiotics. 2020;9:480.

15. Osaili TM, Hasan F, Dhanasekaran DK, Obaid RS, Al-Nabulsi AA, Ayyash M, Karam L, Savvaidis IN, Holley R. Effect of active essential oils added to chicken tawook on the behaviour of Listeria monocytogenes, Salmonella spp. and Escherichia coli O157: H7 during storage. Int J Food Microbiol. 2021;337:108947.

16. Abdullahi M, Adeniji SE. In-silico Molecular Docking and ADME/Pharmacokinetic Prediction Studies of Some Novel Carboxamide Derivatives as Anti-tubercular Agents. Chem Afr. 2020;3:989-1000.

17. Abdullahi M, Shallangwa GA, Uzairu A. In silico QSAR and molecular docking simulation of some novel aryl sulfonamide derivatives as inhibitors of H5N1 influenza A virus subtype. Beni-Suef Univ J Basic Appl Sci. 2020;9:2.

18. Kachur K, Suntres Z. The antibacterial properties of phenolic isomers, carvacrol and thymol. Crit Rev Food Sci Nutr. 2020;60:3042-53.

19. Pereira WA, Pereira CD, Assunção RG, da Silva IS, Rego FS, Alves LS, Santos JS, Nogueira FJ, Zagmignan A, Thomsen TT, Løbner-Olesen A. New insights into the antimicrobial action of cinnamaldehyde towards Escherichia coli and its effects on intestinal colonization of mice. Biomolecules. 2021;11:302.

20. Chouhan S, Sharma K, Guleria S. Antimicrobial activity of some essential oils- present status and future perspectives. Medicines. 2017:4(3):58.

21. Marchese A, Orhan IE, Daglia M, Barbieri R, Di Lorenzo A, Nabavi SF, Gortzi O, Izadi M, Nabavi SM. Antibacterial and antifungal activities of thymol: a brief review of the literature. Food Chem. 2016;210:402-14.

22. Fall-Niang NK, Sambe-Ba B, Seck A, Deme SN, Wane AA, Bercion $R$, Alambedji-Bada R, Gassama-Sow A. Antimicrobial resistance profile of Salmonella isolates in chicken carcasses in dakar, Senegal. Foodborne Pathogens Dis. 2019;16:130-6.

23. Streicher LM. Exploring the future of infectious disease treatment in a post-antibiotic era: a comparative review of alternative therapeutics. J Glob Antimicrob Resist. 2021;24:285-95.

24. Elshaghabee FM, Rokana N. Dietary management by probiotics, prebiotics and synbiotics for the prevention of antimicrobial resistance. Sustainable Agriculture Reviews 49. Cham: Springer; 2021. p. 33-56.

25. Gupta PD, Birdi TJ. Development of botanicals to combat antibiotic resistance. J Ayurveda Integr Med. 2017;8:266-75.

26. Prasad MA, Zolnik CP, Molina J. Leveraging phytochemicals: the plant phylogeny predicts sources of novel antibacterial compounds. Future Sci OA. 2019;5:FSO407.

27. Pinzi L, Rastelli G. Molecular docking: Shifting paradigms in drug discovery. Int J Mol Sci. 2019;20:4331.

28. Jia Z, Song X, Shi J, Wang W, He K. Transcriptome-based drug repositioning for coronavirus disease 2019 (COVID-19). Pathogens Dis. 2020;78:ftaa036.

29. Daina A, Michielin O, Zoete V. SwissADME: a free web tool to evaluate pharmacokinetics, drug-likeness and medicinal chemistry friendliness of small molecules. Sci Rep. 2017:7:1-3.

30. van Waterschoot RA, Schinkel AH. A critical analysis of the interplay between cytochrome P450 3A and P-glycoprotein: recent insights from knockout and transgenic mice. Pharmacol Rev. 2011;63:390-410.
31. Alminderej F, Bakari S, Almundarij TI, Snoussi M, Aouadi K, Kadri A. Antioxidant activities of a new chemotype of Piper cubeba L. fruit essential oil (methyleugenol/eugenol): In Silico molecular docking and ADMET studies. Plants. 2020;9:1534.

32. Banerjee P, Eckert AO, Schrey AK, Preissner R. ProTox-II: a webserver for the prediction of toxicity of chemicals. Nucleic acids Res. 2018;46:257-63.

33. Braga RC, Alves VM, Muratov EN, Strickland J, Kleinstreuer N, Trospsha A Andrade CH. Pred-skin: a fast and reliable web application to assess skin sensitization effect of chemicals. J Chem Inf Model. 2017:57:1013-7.

34. Morris GM, Huey R, Lindstrom W, Sanner MF, Belew RK, Goodsell DS, Olson AJ. AutoDock4 and AutoDockTools4: automated docking with selective receptor flexibility. J Comput Chem. 2009;30:2785-91.

35. Valero-Pacheco N, Blight J, Aldapa-Vega G, Kemlo P, Pérez-Toledo M, Wong-Baeza I, Kurioka A, Perez-Shibayama C, Gil-Cruz C, Sánchez-Torres $L E$, Pastelin-Palacios R. Conservation of the OmpC porin among typhoidal and non-typhoidal Salmonella serovars. Front Immunol. 2020;10:2966.

36. Sheikh J, Czeczulin JR, Harrington S, Hicks S, Henderson IR, Le Bouguénec C, Gounon P, Phillips A, Nataro JP. A novel dispersin protein in enteroaggregative Escherichia coli. J Clin Investig. 2002;110:1329-37.

37. Abdelrheem DA, Rahman AA, Elsayed KN, Abd El-Mageed HR, Mohamed HS, Ahmed SA. Isolation, characterization, in vitro anticancer activity, dft calculations, molecular docking, bioactivity score, drug-likeness and admet studies of eight phytoconstituents from brown alga sargassum platycarpum. J Mol Struct. 2021;1225:129245.

38. Okaiyeto K, Ojemaye MO, Hoppe H, Mabinya LV, Okoh Al. Phytofabrication of silver/silver chloride nanoparticles using aqueous leaf extract of Oedera genistifolia: characterization and antibacterial potential. Molecules. 2019;24:4382.

39. De Jong WH, Borm PJ. Drug delivery and nanoparticles: applications and hazards. Int J Nanomed. 2008;3:133.

40. Liu J, Huang Y, Kumar A, Tan A, Jin S, Mozhi A, Liang XJ. pH-sensitive nano-systems for drug delivery in cancer therapy. Biotechnol adv. 2014;32:693-710.

41. McClements DJ. Advances in nanoparticle and microparticle delivery systems for increasing the dispersibility, stability, and bioactivity of phytochemicals. Biotech Adv. 2020;38:107287.

42. Vijay D, Dhaka P, Vergis J, Negi M, Mohan V, Kumar M, Doijad S, Poharkar K, Kumar A, Malik SS, Barbuddhe SB. Characterization and biofilm forming ability of diarrhoeagenic enteroaggregative Escherichia coli isolates recovered from human infants and young animals. Comp Immunol Microbiol Infect Dis. 2015;38:21-31.

43. Nair A, Balasaravanan T, Malik SS, Mohan V, Kumar M, Vergis J, Rawool DB. Isolation and identification of Salmonella from diarrheagenic infants and young animals, sewage waste and fresh vegetables. Vet World. 2015;8:669.

44. Gourkhede DP, Bhoomika S, Pathak R, Yadav JP, Nishanth D, Vergis J, Malik SV, Barbuddhe SB, Rawool DB. Antimicrobial efficacy of cecropin A (1-7)-melittin and lactoferricin (17-30) against multi-drug resistant Salmonella Enteritidis. Microb Pathog. 2020;147:104405.

\section{Publisher's Note}

Springer Nature remains neutral with regard to jurisdictional claims in published maps and institutional affiliations.

\footnotetext{
Ready to submit your research? Choose BMC and benefit from:

- fast, convenient online submission

- thorough peer review by experienced researchers in your field

- rapid publication on acceptance

- support for research data, including large and complex data types

- gold Open Access which fosters wider collaboration and increased citations

- maximum visibility for your research: over 100M website views per year
}

At BMC, research is always in progress.

Learn more biomedcentral.com/submissions 